\title{
Fenotipagem de raízes de milho visando tolerância à seca: Uma revisão
}

\author{
Roots phenotyping in maize aiming drought tolerance: A review \\ Fenotipado de raíces en maíz con miras a la tolerancia a la sequía: Una revisión
}

Recebido: 16/06/2021 | Revisado: 22/06/2021 | Aceito: 25/06/2021 | Publicado: 11/07/2021

Crislene Vieira dos Santos

ORCID: https://orcid.org/0000-0003-2204-8673 Universidade Federal de Viçosa, Brasil

E-mail: crislene.santos@ufv.br

Flávio Araújo de Moraes

ORCID: https://orcid.org/0000-0003-4765-7272 Universidade Federal de Lavras, Brasil

E-mail: flavioaraujodemoraes@gmail.com

Luciane Gonçalves Torres

ORCID: https://orcid.org/0000-0002-6869-944X Universidade Federal de Lavras, Brasil E-mail: lucianetorres21@ hotmail.com Ruane Alice da Silva ORCID: https://orcid.org/0000-0003-4039-5038 Long Ping High Tech, Brasil

E-mail: ruane.alice29@gmail.com

Karla Jorge da Silva

ORCID: https://orcid.org/0000-0002-6069-0619 Embrapa Milho e Sorgo, Brasil E-mail: karla.js@hotmail.com

Silvino Guimarães Moreira

ORCID: https://orcid.org/0000-0002-3631-0305 Universidade Federal de Lavras, Brasil

E-mail: silvinomoreira@ufla.br

Cícero Beserra de Menezes

ORCID: https://orcid.org/0000-0001-9437-6946 Embrapa Milho e Sorgo, Brasil

E-mail: cicero.menezes@embrapa.br

Aluízio Borém

ORCID: https://orcid.org/0000-0003-1386-5903 Universidade Federal de Viçosa, Brasil

E-mail: prof.borem@gmail.com

\begin{abstract}
Resumo
Sabe-se que, as plantas adquiriram e adaptaram mecanismos de tolerância, como: sistema radicular mais extenso e com maior relação raiz/parte aérea, alterações de comportamento da frequência estomática, cutícula foliar mais espessa, mudanças de ângulo foliar, acúmulo de metabólitos, ajuste osmótico e a resistência à desidratação de células. Estas modificações adaptativas podem ser particulares de cada genótipo, e envolver diversos mecanismos que podem ser eficientes no uso da água. Dessa forma, o objetivo do presente trabalho foi mostrar que as técnicas de fenotipagem de raízes tem mostrado ferramentas propulsoras da seleção mais eficiente para a tolerância à seca em milho. Para isso foram utilizados trabalhos da base de dados SciELO, Google Scholar, artigos acadêmicos e livros publicados, com relevância para o tema em questão. E com base nestes estudos foi possível compreender que a aquisição de água e nutrientes pelo sistema radicular e sua capacidade de exploração do solo, compõem a base para o desenvolvimento vegetal, sendo um fator resposta para o início do desenvolvimento, e determinante para a produção de grãos. Além disso, com a fenotipagem radicular há vantagens de seleção por meio de mais um critério, que não somente a fenotipagem em campo. Deste modo, pode-se admitir uma economia de tempo e investimento financeiro, além do desenvolvimento de tecnologia com a validação da fenotipagem radicular.
\end{abstract}

Palavras-chave: Sistema radicular; Seleção fenotípica; Zea mays.

\begin{abstract}
It is known that plants have acquired and adapted tolerance mechanisms, such as: more extensive root system and greater root/shoot ratio, changes in stomatal frequency behavior, thicker leaf cuticle, changes in leaf angle, accumulation of metabolites, osmotic adjustment and resistance to cell dehydration. These adaptive modifications can be specific to each genotype, and involve several mechanisms that can be efficient in water use. Thus, the objective of the present work was to show that root phenotyping techniques have been shown to be the most efficient driving tools of selection for drought tolerance in corn. For this, works from the SciELO database, Google Scholar, academic
\end{abstract}


articles and published books were used, relevant to the topic in question. And based on these studies, it was possible to understand that the acquisition of water and nutrients by the root system and its capacity to exploit the soil, form the basis for plant development, being a response factor for the beginning of development, and determinant for the grains yield. Furthermore, with root phenotyping there are selection advantages through one more criterion, other than field phenotyping. Thus, it is possible to admit a saving of time and financial investment, in addition to the development of technology with the validation of root phenotyping.

Keywords: Root system; Phenopytic selection; Zea mays.

\section{Resumen}

Se sabe que las plantas han adquirido y adaptado mecanismos de tolerancia, tales como: sistema radicular más extenso y mayor relación raíz / brote, cambios en el comportamiento de frecuencia estomática, cutícula foliar más gruesa, cambios en el ángulo foliar, acumulación de metabolitos, ajuste osmótico y resistencia a deshidratación celular. Estas modificaciones adaptativas pueden ser específicas de cada genotipo e implican varios mecanismos que pueden ser eficientes en el uso del agua. Así, el objetivo del presente trabajo fue mostrar que las técnicas de fenotipado de raíces han demostrado ser las herramientas impulsoras más eficientes de selección para la tolerancia a la sequía en maíz. Para ello se utilizaron trabajos de la base de datos SciELO, Google Scholar, artículos académicos y libros publicados, relevantes al tema en cuestión. Y a partir de estos estudios se pudo comprender que la adquisición de agua y nutrientes por parte del sistema radicular y su capacidad de aprovechamiento del suelo, constituyen la base del desarrollo vegetal, siendo un factor de respuesta para el inicio del desarrollo, y determinante para la producción de granos. Además, con el fenotipado de raíces existen ventajas de selección a través de un criterio más, además del fenotipado de campo. Así, es posible admitir un ahorro de tiempo e inversión económica, además del desarrollo de tecnología con la validación del fenotipado radicular.

Palabras clave: Sistema radicular; Selección fenópica; Zea mays.

\section{Introdução}

O milho (Zea mays) é um dos cereais mais cultivados e consumidos do mundo, apresentando grande importância no cenário global para a segurança alimentar, devido à sua alta qualidade nutricional. O milho ocupa a terceira posição no ranking mundial de consumo de cereais, atrás apenas do arroz e do trigo, com importância econômica, cultural e social, pelas suas diversas utilizações, desde a alimentação humana e animal, até a indústria de biocombustíveis (Magalhães et al., 2014). De acordo com a Companhia Nacional de Abastecimento (2021) a produção brasileira de milho deve atingir 105,5 milhões de toneladas na safra 2020/2021, 2,9\% a mais do que na safra de 2019/2020. No contexto mundial, o Brasil ocupa a terceira posição entre os maiores produtores de milho, precedido por Estados Unidos e China. Na média dos últimos cinco anos, o Brasil apresenta uma posição de destaque, sendo o segundo maior exportador mundial de milho, atrás apenas dos Estados Unidos (CONAB, 2020). Na safra 2019/2020 o país exportou 34,8 milhões de toneladas, considerando o período de fevereiro de 2019 a janeiro de 2020.

O milho pertence à família das gramíneas, tendo como centro de origem e diversidade o México e América Central, respectivamente. Contudo, a cultura se expandiu de maneira crescente ao longo dos anos, e, atualmente esse é cultivado em praticamente todas as regiões do globo, por apresentar alta adaptabilidade. Essa adaptabilidade foi obtida através de décadas de melhoramento genético e seleção de materiais, que permitiram, inclusive, o cultivo em segunda safra, com plantios realizados até meados de fevereiro, ampliando a produção nacional. No Brasil o milho é cultivado nas épocas de safra (agosto a janeiro) com 33\% da produção, e segunda safra ou safrinha (janeiro a julho), que corresponde aos $67 \%$ restantes. Com a expectativa de propulsão da segunda safra, a produção de milho deve enfrentar consequências mais severas de estresses abióticos, pois nesse período, ocorre a redução de radiação solar e temperatura e principalmente déficit hídrico que mais compromete o desenvolvimento das plantas e a produtividade de grãos, quando os períodos de estiagem são prolongados (Fritsche-Neto \& Borém, 2011).

A modernização da agricultura, técnicas de manejo e melhoramento genético permitiram o aumento produtivo de praticamente todas as culturas (Vencovsky \& Ramalho, 2010). Contudo, manter a produção na escala crescente é um desafio, que se torna cada vez mais essencial, com as mudanças climáticas cada vez mais frequentes, e, consequentemente a limitação 
de recursos minerais e hídricos (UK Government, 2011). De acordo com o USDA (2015), em 2050 haverá 9,1 bilhões de pessoas no mundo. Ou seja, aproximadamente 2 bilhões a mais do que hoje, o que alarma ainda mais para a importância do melhoramento de plantas e da capacidade de tornar as culturas cada vez mais responsivas às mudanças climáticas. Neste contexto, estima-se que as perdas na produção de grãos de milho sejam de 15 a $20 \%$, devido aos estresses abióticos, mais especificamente ao estresse hídrico.

A cultura do milho apresenta uma correlação significativa entre o desenvolvimento de raízes seminais e a produção da planta adulta e quando as plantas estão em condições de estresse, estas buscam amenizar o impacto causado, reduzindo a transpiração e aumentando a eficiência de aquisição de água do solo. Dessa forma, o sistema radicular tem uma participação essencial para as plantas por ser o primeiro órgão sensível à escassez de água (Trachsel et al., 2010), sendo ainda que, sua capacidade de exploração do solo, compõem a base para o desenvolvimento vegetal, o que é determinante para a produção de grãos. Dessa forma, diversos programas de melhoramento de milho têm direcionado as pesquisas para o desenvolvimento de estratégias de fenotipagem radicular de alta precisão para selecionar genótipos adaptados às condições de estresse hídrico (Blum, 2009).

\section{Metodologia}

Este trabalho caracteriza-se por uma revisão de literatura com base em trabalhos conceituados e atuais a respeito das técnicas de fenotipagem radicular de milho visando o melhoramento genético para tolerância ao estresse hídrico. Por meio de pesquisa eletrônica foram selecionados artigos das bases de dados Google Scholar e Scientific Eletronic Library (SciELO). Para ampliar as informações e cunho científico deste trabalho foram utilizados artigos, capítulos de livro e outras informações técnicas encontradas em fontes seguras da internet. A pesquisa realizada foi de natureza qualitativa, seguindo os padrões de metodologia científica trabalhados por Pereira et al. (2018). Os trabalhos utilizados como fonte tratam de assuntos como fenotipagem radicular, equipamentos de scanner, metodologia de fenotipagem, melhoramento de milho, estresse abiótico. E isto, considerando ainda a utilização de trabalhos publicados nos últimos 10 anos. Os estudos encontrados foram analisados criticamente, de maneira prévia a inserção no presente estudo, com objetivo de acrescentar apenas informações relevantes e práticas a respeito dos métodos de fenotipagem.

\section{Revisão da Literatura}

\subsection{Novas ferramentas no melhoramento genético de milho para seleção de tolerância à seca}

Estima-se que 70\% da água potável do mundo é consumida pela irrigação, para produzir alimentos, fibras, madeira e biocombustíveis, dentre outros. Por isso, a disponibilidade de água é um fator limitante para a produção das espécies, que têm sido submetidas aos estresses cada vez mais severos, principalmente o estresse hídrico. Além disso, do total de água absorvido pelas plantas, pouco mais de $1 \%$ é retido e utilizado nos processos fisiológicos, sendo $99 \%$ demandado pela transpiração. Assim, qualquer desbalanço hídrico pode culminar em modificações bioquímicas e fotossintéticas que, em geral, serão traduzidas em menor produção de grãos (Durães et al., 2004). Dessa forma, a contribuição atual e futura do melhoramento de plantas tem se encaminhado para seleções precoces, e que envolvem mais parâmetros genéticos para tolerância a seca e para eficiência de uso da água. Com isso, a fenotipagem radicular tem ganhado espaço nos estudos de eficiência de absorção de água e nutrientes do solo. Isto porque, faltam estudos de tolerância à seca para raízes, comparado aos estudos com folhas e caule, e pela importância que estes órgãos tem para estabelecimento da planta, síntese de moléculas e sinalização de estresse, dentre outras (Hodge et al., 2009).

A fenotipagem de raízes tem sido uma estratégia importante para a tolerância à seca, que aplicada nas fases iniciais de desenvolvimento das plantas deve acelerar o processo de seleção. Para tais estudos existem diversas metodologias associadas à 
fenotipagem de alto desempenho, que deverá aumentar a precisão e minimizar os efeitos da interação genótipos ambientes (Fritsche-Neto \& Borém, 2011). Estas metodologias tem sido aplicadas para a fenotipagem em larga escala com uso de softwares e plataformas para análise de imagens radiculares. Estas técnicas podem ser destrutivas, ou ex situ, e in situ ou não destrutivas. As técnicas ex situ utilizam todo o sistema radicular como amostra, fora de seu ambiente de cultivo, enquanto as técnicas in situ avaliam as amostras in loco, no ambiente de cultivo (Fritsche-Neto \& Borém, 2015). Algumas metodologias serão abordadas nos tópicos seguintes, bem como suas aplicações e perspectivas para o melhoramento genético de plantas.

\subsection{Metodologia de fenotipagem radicular ex situ}

De acordo com Fort et al. (2012), as raízes desenvolvem mais estratégias adaptativas, quando submetidas ao baixo nível de água e nutrientes, do que os órgãos aéreos. Ou seja, para verificar a dinâmica de crescimento e desenvolvimento é preciso utilizar um ambiente artificial controlado. Isso amplia a capacidade de captura de imagens para observação de parâmetros que culminam em reflexos na produtividade (Liu et al., 2010). Contudo, a fenotipagem radicular inicial deve ser correlacionada à fenotipagem nos estágios finais, que tem sua expressão muito influenciada pela interação genótipo x ambiente (Mano et al., 2007; Burton \& Lynch 2010; Saengwilai, 2013).

Inicialmente, caracteres como ângulo radicular, comprimento, diâmetro médio, área superficial total, área específica e volume de exploração das raízes são variáveis importantes para discriminar os materiais quanto ao sistema radicular (Souza et al., 2016). Por estes parâmetros é possível calcular outras variáveis secundárias de maior herdabilidade. A expressão dos genótipos deve ser observada sob estresse, em que serão notadas modificações típicas, classificando raízes para a tolerância à seca, que pode demonstrar também a eficiência biológica das plantas (Ziyomo \& Bernardo, 2013).

Como estratégias para melhorar as avaliações a hidroponia, aeroponia têm sido utilizadas para facilitar a visualização. Além disso, outros recursos como vasos plásticos, cilindros de PCV, tubetes ou cultivo em ágar também são opções para cultivo em ambiente controlado. A hidroponia, neste caso, não é uma técnica eficiente para estudo de estresse hídrico, que deve ser realizado sob condições limitantes. Mas, as demais técnicas têm sido bem aplicadas para acelerar a seleção no programa de melhoramento genético.

O plantio em tubetes é um método eficiente para otimização de espaço utilizado, mas seu volume deve ser repensado de acordo com a espécie em estudo ou com o tempo de duração do ensaio. Para o milho têm sido utilizados tubetes de 100 a $400 \mathrm{~cm}^{3}$, com avaliações realizadas entre 20 a 40 dias após a semeadura. Ou seja, o tempo de estresse é de até 40 dias, em geral, com posterior retirada das raízes, para lavagem. A indicação é de que um saco plástico seja colocado dentro do tubete para evitar o contato das raízes com as paredes do tubete. Este cuidado pode evitar a perda de raízes finas, que poderiam estar grudadas nas paredes do tubete. Porém, apesar das vantagens de economia de tempo e espaço físico, este procedimento é trabalhoso, e modifica a configuração espacial e a arquitetura radicular. As implicações acerca dessa interferência ainda não são totalmente precisas (Mairhofer et al., 2013).

\subsection{Varredura digitalizada}

A avaliação de caracteres do sistema radicular pode se dar por meios manuais e/ou com aplicação de tecnologia de obtenção de dados. O uso de aparatos tecnológicos é uma alternativa para contribuir para com a avaliação manual e minimizar quaisquer erros, garantindo uma maior acurácia dos dados. Imagens digitalizadas das raízes vêm sendo utilizadas em diversas culturas a fim de obter dados do sistema radicular como o volume e a área ocupada pelas raízes. A obtenção dessas imagens dá-se por meio de escaneamento digital e as análises por meio de softwares especializados (Zuffo et al., 2019). 


\subsubsection{Amostras}

Para realizar a varredura digitalizada das raízes e obtenção das imagens que serão processadas por meio de softwares como o WinRHIZO, é importante seguir o protocolo de arranjo do material disponível em manuais. Posiciona-se uma placa de acrílico no scanner e acrescenta-se uma pequena quantidade de água que seja suficiente para cobrir as raízes. Coloca-se sobre a placa o material coletado, que deve estar devidamente lavado para remoção de impurezas. É necessário atentar-se para a organização das raízes evitando a sobreposição ou o cruzamento das mesmas. Ao organizá-las é primordial o uso de material não cortante para que o acrílico não sofra arranhaduras que poderiam ser erroneamente consideradas como raízes pelos softwares (Kamoshita et al., 2019).

\subsubsection{Protocolo de escaneamento}

Após o correto arranjo das raízes na bandeja que está posicionada no aparelho, é feito o processo de escaneamento. A resolução das imagens deve ser entre 300-600 pontos por polegada (dpi), levando em consideração a espessura das raízes. Para análise no software WinRHIZO ${ }^{\mathrm{TM}}$, por exemplo, o manual do fabricante recomenda o uso de 450 dpi (Kamoshita et al., 2019). As imagens devem ser salvas em formato TIFF que permite a redução da presença de ruídos nas imagens digitalizadas, e a análise é feita em tons de cinza, promovendo uma redução no tamanho das imagens (Kamoshita et al., 2019). Em seguida, as imagens obtidas sofrem o processo de binarização, onde cada pixel assume somente o valor 0 (preto) ou 1 (branco) permitindo a separação dos objetos de interesse (raízes) do fundo da imagem (Filho \& Neto, 1999).

\subsection{Avaliações por software WinRHIZO}

Especialmente desenvolvido para análise de raízes lavadas, o software WinRHIZO ${ }^{\mathrm{TM}}$ produzido pela Regent Instruments Inc, é um dos mais utilizados em trabalhos cujo objetivo é a mensuração de variáveis do sistema radicular da cultura do milho. Dentre as variáveis, pode-se obter caracteres morfológicos, como o comprimento, área e volume, além de arquitetura e cor. Ao fim das análises os resultados são salvos em formato .TXT podendo ser convertido em um arquivo excel permitindo a visualização de vários parâmetros (Kamoshita et al., 2019).

$\mathrm{O}$ aparato consiste em um equipamento de aquisição de imagens, como scanners de mesa e um sistema de processamento de imagens. O software se mostra sensível protocolo de digitalização que, se feito corretamente, permite uma determinação rigorosa dos valores de comprimento e diâmetro das raízes. Além disso, a resolução do scanner interfere nas análises feita pelo software, como o comprimento das raízes que pode apresentar valores maiores. Mas é preciso atentar-se para o uso de altas resoluções, pois é necessário memória disponível no computador para realizar a varredura completa (Bouma et al., 2000).

Magalhães et al. (2014) utilizaram o programa WinRHIZO ${ }^{\mathrm{TM}}$ para mensurar as variáveis do sistema radicular de plantas de milho. As variáveis obtidas foram: comprimento, diâmetro, volume e área superficial das raízes de acordo com a classe do diâmetro, sendo elas: raízes muito finas ( $\varnothing$ inferior a $0,5 \mathrm{~mm}$ ), raízes finas $(>0,5 \emptyset<2,0 \mathrm{~mm}$ ) e raízes grossas $(\varnothing>$ 2,0 mm). O programa disponibiliza uma maior quantidade de classes, mas o uso de uma quantidade inferior vem sendo feito por diversos pesquisadores afim de simplificar as análises. Hund et al. (2009) também realizaram a separação das raízes de acordo com classes diâmetros, neste caso apenas duas contendo as raízes axilares (pequeno diâmetro) e laterais (grande diâmetro). As classes foram definidas no tamanho de 42 micrômetros $(\mu \mathrm{m})$.

$\mathrm{O}$ teor de fósforo (P) no solo é um fator que interfere no desenvolvimento de plantas de milho. Avaliando o sistema radicular de plantas de milho afim de identificar e selecionar genótipos que melhor se adaptem à solos com diferentes concentrações de P, Magalhães et al. (2011), realizaram um experimento com dois níveis de P, alto $\left(20 \mathrm{mg} / \mathrm{dm}^{3}\right.$ de solo) e baixo ( $4 \mathrm{mg} / \mathrm{dm}^{3}$ de solo). Foram obtidos caracteres do sistema radicular com o uso do software WinRHIZO ${ }^{\mathrm{TM}}$ e estes 
resultados possibilitaram a conclusão de que o sistema radicular apresenta maior área superficial e comprimento radicular em baixas concentrações de P. As imagens escaneadas e analisadas pelo programa, permitiram também a distinção de genótipos de milho em ambientes com baixo teor de P.

\subsection{Avaliações por outros softwares}

Desenvolvido pelo Brasil, um outro software de análise de sistema radicular que permite bons resultados para a cultura do milho é o SAFIRA (Sistema para Análise de Fibras e Raízes). Lançado pela Embrapa Instrumentação Agropecuária em 2010, é um sistema de distribuição gratuita de fácil utilização, que permite a obtenção de variáveis importantes como o comprimento, área e volume das raízes (Jorge \& Silva, 2010).

As condições físicas do solo afetam diretamente o desenvolvimento do sistema radicular das plantas. A fim de incluir as condições físicas do solo na modelagem do crescimento radicular de plantas de soja e milho, Moraes (2017), desenvolveu uma pesquisa cultivando estas culturas em quatro diferentes níveis de compactações de solo e avaliou o conteúdo volumétrico de água, a resistência do solo à penetração e a densidade de comprimento radicular. As raízes foram coletadas, separadas e devidamente lavadas para captura de imagens através de scanner. Em seguida, as imagens foram processadas utilizando o software Safira e o comprimento radicular foi determinado. Com isso, o peso e o comprimento das raízes de cada amostra foram relacionados ao peso total da amostra afim de mensurar o comprimento total do sistema radicular. Os dados obtidos foram estudados e o autor concluiu que a compactação afetou diretamente na produtividade de grãos que foi reduzida e a densidade de comprimento radicular simulada foi similar aos valores medidos em condições de campo.

Outro software utilizado para processamento de imagens de amostra de raízes lavadas é o IJ_Rhizo. É um macro para ImageJ que é um programa de processamento de imagens. De simples utilização para cientistas não programadores é um software de código aberto, um programa simples que automatiza uma série de comandos e adiciona funções para a realização das medidas das raízes. Por ser de código aberto permite modificações que atendam às necessidades do usuário e vem sendo executado em uma gama de sistemas operacionais como Linux e Windows para análise de imagens de raízes de diferentes culturas como milho e arroz (Pierret et al., 2013).

O aplicativo RootNav é uma ferramenta que vem sendo cada vez mais utilizada para análise de imagens de raízes para diversas culturas entre elas o milho. É uma ferramenta semiautomática que apresenta abordagem top-down (de cima para baixo), tendo o ponto de partida definido pelo usuário para definir um caminho do modelo. São necessários vários parâmetros de modelo, mas estes são fixos para diversas culturas facilitando a execução do comando. Estes modelos são disponibilizados pela interface do RootNav que possibilita a modificação pelos usuários, de acordo com o objetivo da avaliação (Pound et al., 2013).

\subsection{Metodologia de fenotipagem radicular in situ}

O termo original para a fenotipagem de alto desempenho é High-thoroughput phenotyping platforms, onde é possível aumentar a capacidade de coleta de caracteres, promovendo a ação simultânea com a genômica. Neste contexto, as observações podem ser associadas às variáveis climáticas e ao monitoramento de características, por sensores acoplados às plantas, quantificando taxa de evapotranspiração, alocação de carbono, e índices vegetativos (absorção de luz visível, reflexão de infravermelho, dentre outras). As características são alcançadas principalmente pela análise de imagens aéreas, com fotografia de luz e microscopia, ou por técnicas mais modernas como termografia, fluorescência, tomografia, ressonância magnética e ressonância nuclear (Berger et al., 2010). Com grande volume de dados a fenômica se apresenta multidisciplinar, integrando a biologia molecular, fisiologia, genética, informática, estatística e outras ciências. Estas estratégias são integradas a fim de acurar modelos de predição, admitindo maior confiabilidade nos resultados (Cortes et al., 2017). 


\subsection{Obtenção de imagens e softwares}

Para a análise de imagens obtidas de forma in situ, o software SAFIRA também é uma alternativa desde que a captação das imagens e a análise possam se dar de formas distintas. Valadão et al. (2015) realizaram experimento para avaliar diferentes doses de adubação fosfatada e a compactação do solo pelo tráfego de máquinas no sistema radicular de plantas de milho. Para análise das raízes foram feitas trincheiras transversais expondo o sistema radicular que foi então fotografado por câmera digital para obtenção das imagens. Os resultados das análises das imagens permitiram que os autores observassem que houve uma influência da área ocupadas das raízes pela compactação e a forma de adubação. Além disso, foi possível observar que as raízes apresentaram uma redução do diâmetro médio e uma maior emissão de raízes laterais pelas plantas com o aumento da compactação. O uso do software SAFIRA se mostrou eficiente para a análise do sistema radicular das plantas.

A empresa Bio-Science desenvolveu um scanner de raízes portátil, que capta imagens digitais in situ com até $360^{\circ} \mathrm{e}$ alta resolução (até 600dpi), o CI-600. Sem destruição de amostras, este aparelho permite o acompanhamento do crescimento das raízes e o comportamento do sistema radicular durante todo o ciclo da planta ou por período determinado. As imagens captadas podem ser analisadas por meio do software RootSnap que calcula parâmetros como comprimento, diâmetro, área e volume. Guimarães et al. (2017) avaliaram o desenvolvimento do sistema radicular de acessos de arroz em terras altas submetidos à déficit hídrico ou não. Para isso, captaram imagens do sistema radicular aos 33 e 44 dias após o plantio utilizando o scanner de raiz CI-600 Cano Scan e o programa WinRHIZO para análise das imagens obtidas e conversão em dados. Foram coletados dados de comprimento, volume e classes de porcentagem de comprimento de acordo com duas classes de diâmetros definidas. $\mathrm{O}$ autor observou e classificou acessos com sistema radicular bem distribuído, profundo e espesso; características de interesse para a cultura em relação ao déficit hídrico. O uso do scanner foi uma maneira eficiente de obter imagens do sistema radicular sem a necessidade de destruição das plantas.

O software Rootsnap foi utilizado para análise de imagens obtidas de raízes de gramíneas pelo aparelho CI-100 em um estudo cujo objetivo foi comparar o padrão de crescimento de diferentes gramíneas durante o período de 2 anos, uma vez que a arquitetura dessas plantas influencia na invasão de espécies não nativas da área. Foram analisadas sete diferentes profundidades de solo uniformemente espaçadas e foram registradas medidas de comprimento das raízes finas ( $2 \mathrm{~mm}$ de diâmetro) utilizando o aparelho portátil de scanner. As imagens foram posteriormente avaliadas utilizando o software Rootsnap rastreando as raízes através do toque manual à tela. Os autores observaram que houve interação entre a quantidade de novas raízes entre os três estágios de crescimento e três profundidades avaliadas e que regiões dominas por determinada gramínea contribui para o estabelecimento da Carduus nutans uma planta invasora da região (Han \& Young, 2014).

\subsection{Tomografia computadorizada de raio $\mathrm{X}$}

Na ciência do solo, o uso de tomografia computadorizada de raio X gama é uma alternativa para o estudo, por exemplo, da distribuição de água no perfil do solo e a umidade do meio. Os tomógrafos foram desenvolvidos a princípio para uso médico, sendo aparelhos de alto custo de produção e não adaptados para uso em pesquisas agrárias. Com isso, o desenvolvimento de aparelhos adaptados se tornou uma realidade e foram desenvolvidos novos equipamentos com variadas características que permitiam a pesquisa aplicada à Física do Solo. Um exemplo de aparelho desenvolvido é o Minitomógrafo de raios-X gama de propriedade da Embrapa Instrumentações Agropecuárias (Neto et al., 2007).

Pedrotti et al. (2003), desenvolveram uma pesquisa a fim de descrever o processo de calibração de um minitomógrafo de raios-X gama para estudo de umidade e densidade do solo. A calibração do aparelho foi feita através de regressão linear entre as unidades tomográficas e os coeficientes de atenuação linear, estes são diretamente proporcionais ao grau de adensamento de compactação em cada ponto de seção transversal da amostra. Os autores defendem que a calibração correta do aparelho é fundamental para o bom desempenho da tomografia computadorizada e o uso dessa técnica permitiu o estudo dos 
parâmetros físicos nos horizontes do solo avaliado apresentando boa precisão e adaptabilidade devido aos valores reduzidos de erro que foram atribuídos ao equipamento.

Além do estudo das características físicas do solo, o uso da tomografia computadorizada é uma alternativa para caracterizar o sistema radicular das plantas sem a necessidade de lavagem das raízes, que muitas vezes promove a quebra das raízes, em especial as mais finas, afetando no resultado obtido. $\mathrm{O}$ uso deste método não destrutivo permite a obtenção de imagens que permitem a visualização de diversos ângulos e mede a atenuação da radiação ionizante que passa pelo objeto analisado. Para que o método seja bem-sucedido é preciso que ele capte especificamente as raízes e seja capaz de se adaptar às mudanças de locais (Mairhofer et al., 2013).

O RooTrack é uma ferramenta que requer interação mínima do usuário e se adapta às mudanças nas estimativas de densidade de raiz. Mairhofer et al. (2012) utilizaram plantas de trigo, milho e tomate para obter dados através da tomografia computadorizada por meio de um scanner de raio-X. Se trata de uma abordagem automatizada de rastreamento de raízes que explora vários modelos de aparência e é capaz de extrair com sucesso diversas arquiteturas de raízes destas plantas, incluindo raízes finas, sendo que o menor tamanho de raiz depende da resolução em que a amostra for digitalizada. RooTrack promete facilitar a fenotipagem de raízes para essas culturas.

Outra ferramenta de software utilizada é o algoritmo de rastreamento automático de raiz RootViz. Tracy et al. (2012), utilizaram essa abordagem para analisar imagens de mudas de três cultivares de trigo a fim de examinar o efeito de microestruturas contrastantes presentes no solo em associação com diferentes níveis de compactação no crescimento das raízes. O software utiliza uma função de probabilidade para determinar se pixels específicos representam raízes, e neste estudo foi capaz de fornecer dados precisos e sem a necessidade de destruição das amostras. RootViz pode ser utilizado para obter uma caracterização dinâmica das respostas de diferentes cultivares de espécies em diferentes níveis de compactação

\subsection{Imagens em 3D}

Outras ferramentas vêm sendo utilizadas para o estudo do sistema radicular sem a necessidade de destruição das amostras, ou seja, de forma in situ. A técnica de ressonância magnética possibilita o estudo da arquitetura tridimensional das raízes podendo acompanhar o desenvolvimento do sistema radicular no decorrer da vida da planta. A metodologia dessa técnica deve ser específica para cada espécie de planta estudada. Para plantas jovens de soja foram analisadas através da captura de imagens tridimensionais para avaliar as respostas morfológicas das raízes a estresses do solo. A técnica apresentou o potencial de fornecer uma imagem detalhada das mudanças ocorridas na morfologia das raízes, o que pode representar um salto na compreensão da dinâmica do crescimento do sistema radicular (Bellian et al., 2005).

A radiografia de nêutrons é uma outra técnica de imagem não invasiva que mede a atenuação dos nêutrons térmicos para caracterizar a composição interna dos materiais. As propriedades hídricas do solo, especialmente na zona radicular, são difíceis de investigar in situ. Com isso, essa abordagem vem sendo utilizada para medir a distribuição espacial e temporal de água nos solos. Plantas de milho e tremoço-branco foram avaliadas a fim de observar a distribuição de água próximo ao sistema radicular em períodos de seca e irrigação. As plantas foram cultivadas por três semanas e por cinco dias foram obtidas imagens da infiltração da água meio de radiografia de nêutrons. Essa técnica permitiu que os autores observassem que a quantidade de água na zona radicular foi maior do que no restante do solo durante e após a infiltração. Além disso, foram observadas regiões em torno de algumas raízes com alta quantidade de água (Esser et al., 2010)

\subsection{Fenômica e genômica aplicadas aos caracteres radiculares}

A eficiência metabólica das raízes está associada ao menor custo energético das plantas para a exploração do solo, que pode ser convertido em maior produção (Lynch, 2015). No milho esta eficiência se traduz na redução do número de raízes 
formadas, associadas ao maior crescimento dessas em profundidade e também ao acúmulo de metabólitos, que podem auxiliar na eficácia para absorção de nutrientes, como nitrogênio e fósforo. Para quantificar a capacidade de absorção de água e nutrientes pelas plantas, a caracterização do sistema radicular tem sido um parâmetro relevante, avaliando sua correlação com desenvolvimento da planta e eficiência na captação de água do solo (Bruce et al., 2002).

As interações dinâmicas entre a base genética e o meio onde estão as plantas, independentemente de estarem sob condições adversas ou ótimas para seu desenvolvimento, desencadeiam fenótipos diversos (Dhondt et al., 2013). Para a obtenção e caracterização de um número maior de dados fenotípicos têm-se utilizado técnicas de fenotipagem de alta qualidade e resolução, chamadas de fenômica (Walter et al., 2015). O uso da fenômica em conjunto com a seleção genômica para estudo de SNPs pode ser a chave para encontrar mecanismos genéticos de tolerância à seca. Para unir os dados fenotípicos e genotípicos obtidos, o desenvolvimento do modelo de predição deve indicar aqueles indivíduos mais predispostos à tolerância à seca, a fim de reduzir o tempo de seleção no programa de melhoramento.

Para aumentar a eficiência da seleção, a junção de informações fenotípicas e genotípicas tem sido associada ao uso de marcadores moleculares correlacionados com a tolerância à seca (Messmer et al., 2009). A seleção assistida é uma estratégia para a identificação de variações alélicas expressas e genes funcionais, presentes no genoma (Hao et al., 2011). Por meio de mapeamento associativo (GWAS), é possível identificar as variações funcionais de genes ligados às características complexas, como a tolerância à seca (Yang et al., 2011). Além disso, modelos de seleção genômica como o GBLUP (Genomic Best Linear Unbiased Predictions), podem fornecer predições precisas, mesmo quando o genótipo ainda não foi avaliado em campo (Azevedo et al., 2015). Isto resulta num progresso significativo para programas de melhoramento, reduzindo número de genótipos testados em campo, e por consequência, minimizando os custos da fenotipagem (Krchov \& Bernardo, 2015).

\section{Considerações Finais}

As técnicas utilizadas são eficientes para realizar a seleção via fenotipagem. Contudo, cada uma dessas deve ser aplicada com base na disponibilidade de mão-de-obra, recursos disponíveis, e que se adapte às condições dos pesquisadores. Neste sentido, o software WinRHIZO tem sido bastante aplicado pela simples interpretação dos dados e aplicação da técnica. A tomografia computadorizada se apresenta como uma técnica mais cara e complexa, que exige mais recursos financeiros para desenvolvimento.

A fenotipagem de raízes é uma estratégia importante que deve ser utilizada para otimizar o tempo de seleção de genótipos desejáveis. Com isso, é importante viabilizar as metodologias e resultados obtidos em trabalhos futuros. Dessa forma, outros pesquisadores obterão maiores informações sobre a fenotipagem, protocolos operacionais, e mesmo, acesso às descrições que facilitem a compra dos equipamentos necessários para uso das técnicas.

\section{Agradecimentos}

Os autores agradecem às instituições de pesquisa CNPq, CAPES, Embrapa Milho e Sorgo pelo apoio à pesquisa e ensino, e às bases de dados SciELO, e Google Acadêmico, que tornaram disponíveis as fontes para realização deste trabalho.

\section{Referências}

Azevedo, C. F., Resende, M. D. V., Silva, F. F., Viana, J. M. S., Valente, M. S. F., Resende, J. R. M. F. R. \& Muñoz, P. (2015). Ridge, Lasso and Bayesian aditive dominance genomic models. BMC Genet, 16, 1 - 13.

Bellian, J. A., Kerans, C., \& Jennette, D. C. (2005). Digital outcrop models: applications of terrestrial scanning lidar technology in stratigraphic modeling. Journal of sedimentary research, 75 (2), $166-176$.

Berger, B., Parent, B. \& Tester, M. (2010). High-throughput shoot imaging to study drought responses. Journal of experimental botany, 61 (13), 3519 - 3528. 
Blum, A. (2009). Effective use of water (EUW) and not water-use efficiency (WUE) is the target of crop yield improvement under drought stress. Field Crops Research, 112, $119-123$.

Bruce, W. B., Edmeades, G. O. \& Barker, T. C. (2002). Molecular and physiological approaches to maize improvement for drought tolerance. Journal of experimental botany, 53 (366), $13-25$.

Bouma, T. J., Nielsen, K. L. \& Koutstaal, B. A. S. (2000). Sample preparation and scanning protocol for computerised analysis of root length and diameter. Plant and Soil, 218 (1), 185 - 196.

Burton, A. L. \& Lynch, J. P. (2010). Phenotypic Evaluation and Genetic Basis of Anatomical and Architectural Traits in the Genus Zea. Tese de doutorado. The Pennsylvania State University, Pennsylvania, United States of America.

CONAB - Companhia Nacional de Abastecimento. $8^{\circ}$ Boletim de Monitoramento Agrícola. Cultivos de verão (2a safra) 2018/2019, cultivos de inverno (Safra 2019). https://www.conab.gov.br/info-agro/safras/graos

Cortes, D. F. M., Catarina, R. S., Barros, G. B. D. A., Arêdes, F. A. S., Silveira, S. F. D., Ferreguetti, G. A., Ramos, H. C. C., Viana, A. P. \& Pereira, M. G. (2017). Model assisted phenotyping by digital images in papaya breeding program. Scientia Agricola, 74 (4), 294 - 302.

Dias, K. O. G., Gezan, S. A., Guimarães, C. T., Nazarian, A., Silva, L. C., Parentoni, S. N., Guimarães, P. E. O., Anoni, C. O., Pádua, J. M. V., Pinto, M. O., Noda, R. W., Ribeiro, C. A. G., Magalhães, J. V., Garcia, A. A. F., Souza, J. C., Guimarães, L. J. M. \& Pastina, M. M. (2018). Improving accuracies of genomic predictions for drought tolerance in maize by joint modeling of additive and dominance effects in multi-environment trials. Heredity, $121,24-37$.

Dhondt, S., Wuyts, N. \& Inzé, D. Cell to whole-plant phenotyping: the best is yet to come. (2013). Trends in Plant Science, 18 (8), 428 - 439.

Durães, F. O. M., Santos, M. X., Gama E. E. G., Magalhães, P. C., Albuquerque, P. E. P. \& Guimarães, C. T. Fenotipagem Associada à Tolerância a Seca em Milho para Uso em Melhoramento, Estudos Genômicos e Seleção Assistida por Marcadores. https://www.infoteca.cnptia.embrapa.br/infoteca/bitstream/doc/487708/1/Circ39.pdf

Esser, H. G., Carminati, A., Vontobel, P., Lehmann, E. H., \& Oswald, S. E. (2010). Neutron radiography and tomography of water distribution in the root zone. Journal of Plant Nutrition and Soil Science, 173 (5), 757 - 764.

Filho, O. M. \& Neto, H. V. (1999). Processamento de Imagens Digital de Imagens. Editora Brasport.

Fort, F., Jouany, C. \& Cruz, P. (2012). Root and leaf functional trait relations in Poaceae species: implications of differing resource acquisition strategies. Journal of Plant Ecology, 2, 1 - 9.

Fritsche-Neto, R. \& Borém, A. (2011). Melhoramento de plantas para condições de estresses abióticos. Editora UFV, Brasil.

Fritsche-Neto, R. \& Borém, A. (2015). Fenômica. Como a Fenotipagem de Próxima Geração Está Revolucionando o Melhoramento de Plantas. Editora UFV.

Guimarães, P. H. (2017). Método para fenotipagem de raiz e mapeamento associativo para tolerância à deficiência hídrica em arroz. Tese de Doutorado, Universidade Federal de Goiás, Goiânia, Brasil.

Han, C. \& Young, S. L. (2014). "Root Growth of Two Perennial Grass Types and Musk Thistle (Carduus nutans) in Temperate Grasslands of North America". Invasive Plant Science and Management, 7 (3), 387 - 397.

Hao, Y., Chen, Z., Wang, Y., Bland, D., Buck, J., Brown-Guedira, G. \& Johnson, J. (2011). Characterization of a major QTL for adult plant resistance to stripe rust in US soft red winter wheat. Theoretical and applied genetics, 123 (8), 1401 - 1411.

Hodge, R., Brasington, J., \& Richards, K. (2009). Analysing laser-scanned digital terrain models of gravel bed surfaces: linking morphology to sediment transport processes and hydraulics. Sedimentology, 56 (7), 2024 - 2043.

Hund, A., Trachsel, S. \& Stamp, P. (2009). Growth of axile and lateral roots of maize: I development of a phenotying platform. Plant and Soil, 325 (1), 335 349.

Jorge, L. A. de C. \& Silva, D. J. C. B. (2010). Safira: Manual de utilização. Editora Embrapa Instrumentação-Livro científico.

Kamoshita A., Deshmukh, V. \& Amezquita N. (2019). User manual for liner core sampler and WinRhizo for root analysis. SATREPS, Colombia.

Krchov, L. M., Gordillo, G. A. \& Bernardo, R. (2015). Multienvironment validation of the effectiveness of phenotypic and genomewide selection within biparental maize populations. Crop Science, 55 (3), 1068-1075.

Liu, G., Frescher, G. T., Pan, X., Cornelissen, J. H. C., Li, Y. \& Dong, M. (2010). Coordinated variation in leaf and root traits across multiple spatial scales in Chinese semi-arid and arid ecosystems. New Phytologist, 188, 543 - 553.

Lynch, J. P. (2015). Root phenes that reduce the metabolic costs of soil exploration: opportunities for 21st century agriculture. Plant, Cell and Environment, $38,1775-1784$.

Magalhães, P. C., Souza, T. C. \& Cantão, F. R. O. (2011). Early evaluation of root morphology of maize genotypes under phosphorus deficiency. Plant, Soil and Environment, 57 (3), 135 - 138.

Magalhães, P. C. \& Durães, F. O. M. (2006). Fisiologia da produção de milho. Embrapa Milho e Sorgo. https://www.infoteca.cnptia.embrapa.br/bitstream/ doc/490408/1/Circ76.pdf

Magalhães, P.C., Lavinsky, A. O., Ávila, R. G., Alves, J. C., Melo, M. D., Junior, C. C. G. \& Melo, H. F. (2014). Caracterização radicular e dos componentes de produtividade em quatro genótipos de milho cultivados sob déficit hídrico. Boletim de pesquisa e desenvolvimento. 111. Sete Lagoas: Embrapa Milho e Sorgo. https://ainfo.cnptia.embrapa.br/digital/bitstream/item/122152/1/bol-111.pdf 
Mairhofer, S., Zappala, S., Tracy, S., Sturrock, C., Bennett, M. J., Mooney, S. J., \& Pridmore, T. P. (2013). Recovering complete plant root system architectures from soil via X-ray $\mu$-computed tomography. Plant methods, 9 (1), 1 - 7.

Mairhofer, S., Zappala, S., Tracy, S. R., Sturrock, C., Bennett, M., Mooney, S. J. \& Pridmore, T. (2012). RooTrak: automated recovery of three-dimensional plant root architecture in soil from X-ray microcomputed tomography images using visual tracking. Plant physiology, 158 (2), 561 - 569.

Mano Y., Omori F., Takamizo T., Kindiger B., Bird R. M., Loaisiga C.vH. \& Takahashi H. (2007). QTL mapping of root aerenchyma formation in seedlings of a maize x rare teosinte 'Zeanicaraguensis' cross. Plant and Soil, 295, $103-113$.

Messmer, R., Y. Fracheboud, M. \& Bänziger. (2009). Drought stress and tropical maize: QTL-by environment interactions and stability of QTLs across environments for yield components and secondary traits. Theory Appl Genetic. 119, 913 - 930.

Moraes, M. T. (2017). Modelagem do crescimento radicular de milho e soja sujeito a estresses hídrico e mecânico em latossolo. Tese de Doutorado, Universidade Federal do Rio Grande do Sul, Faculdade de Agronomia.

Neto, A. T., \& Latado, R. R. (2007). Indução de mutação: ampliação da variabilidade genética para o melhoramento de ornamentais. Ornamental Horticulture, $13,2101-2110$.

Pace, J., N. Lee, H.S., Naik, B., Ganapathy, S. \& Lübberstedt, T. (2014). Analysis of maize (Zea mays L.) seedlingroots with the high-throughput image analysis tool ARIA (AutomaticRoot Image Analysis). PLoS One, 9 (9), 108 - 255

Pedrotti, A., Pauletto, E. A., Crestana, S., Cruvinel, P. E., Vaz, C. M. P., Naime, J. D. M. \& Silva, A. M. D. (2003). Tomografia computadorizada aplicada a estudos de um Planossolo. Pesquisa Agropecuária Brasileira., 38 (7), 819 - 826.

Pereira, A. S., Shitsuka, D. M., Parreira, F. J., \& Shitsuka, R. (2018). Metodologia da pesquisa científica. UFSM.

Pierret, A., Gonkhamdee, S., Jourdan, C. \& Maeght, J. (2013). "IJ_Rhizo: an open-source software to measure scanned images of root samples", Plant and Soil, 373, 531-539.

Pound, M. P., French, A. P., Atkinson, J. A., Wells, D. M., Bennett, M. J. \& Pridmore, T. (2013). RootNav: navigating images of complex root architectures. Plant physiology, 162 (4), 1802 - 1814.

Saengwilai P. (2013) Root traits for efficient nitrogen acquisition and genomewide association study of root anatomical traits in maize (Zea mays L.). Tese de doutorado. The Pennsylvania State University, Pennsylvania, United States of America.

Souza, T. C., Castro, E. M., Magalhães, P. C., Lino, L. O., Alves, E. T. \& Albuquerque, P. (2013). Morphophysiology, morphoanatomy, and grain yield under field conditions for two maize hybrids with contrasting response to drought stress. Acta Physiologia e Plantarum, 35, 3201 - 3211.

Souza, T. C., Magalhães, P. C., Castro, E. M. de, Durte, V. P. \& Lavisky, A. O. (2016). Corn root morphoanatomy at different development stages and yield under water stress. Pesquisa Agropecuária Brasileira, 51 (4), 330 - 339.

Trachsel, S., Stamp, P. \& Hund, A. (2010). Growth of axile and lateral roots of maize: Response to desiccation stress induced by polyethylene glycol 8000 . Maydica, 55, $101-109$.

Tracy, S. R., Black, C. R., Roberts, J. A., MCneill, A., Davidson, R., Tester, M. \& Mooney, S. J. (2012). Quantifying the effect of soil compaction on three varieties of wheat (Triticum aestivum L.) using X-ray Micro Computed Tomography (CT). Plant and Soil, 353 (1), 195 - 208.

UK Government, 2011. Foresight project on global food and farming futures: Trends in food demand production. https://assets.publishing.service.gov.uk/government/uploads/system/uploads/attachment_data/file/288329/11-546-future-of-food-and-farming-report.pdf

USDA. Safra Mundial de Milho. 2015/2016, $11^{\circ}$ Levantamento. https://www.fiesp.com.br/indices-pesquisas-e-publicacoes/safra-mundial-de-milho2/attachment/file-20210611193905-boletimmilhojunho2021/

Valadão, F. C. D. A., Weber, O. L. D. S., Valadão Júnior, D. D., Scapinelli, A., Deina, F. R. \& Bianchini, A. (2015). Adubação fosfatada e compactação do solo: sistema radicular da soja e do milho e atributos físicos do solo. Revista Brasileira de Ciência do Solo, 39 (1), 243 - 255.

Vencovsky, R., \& Ramalho, M. A. P. (2006). Contribuições do melhoramento genético no Brasil. In: Paterniani, E. (Ed.). Ciência, agricultura e sociedade (41 - 74). Embrapa Milho e Sorgo, Brasília.

Walter, A., Liebisch, F. \& Hund, A. (2015). Plant phenotyping: from bean weighing to image analysis. Plant Methods, 11 (14), 1 - 11.

Yang, P. M., Huang, Q. C., Qin, G. Y., Zhao, S. P. \& Zhou, J. G. (2014). Different drought-stress responses in photosynthesis and reactive oxygen metabolism between autotetraploid and diploid rice. Photosynthetica, 52 (2), 193 - 202.

Ziyomo, C. \& Bernardo, R. (2013). Drought tolerance in maize-indirect selection through secondary traits versus genome wide selection. Crop Science, 52, $1269-1275$.

Zuffo, A. M., Aguilera, J. G. \& Oliveira, B. R. (2019). Ciência em foco. Editora Pantanal. 